\title{
Textile Teachers' Pedagogical Content Knowledge and Ghana Senior High School Graduates Participation in Modernisation of Indigenous Textile Industry
}

\author{
Johnson Kofi Kassah $^{1^{*}} \quad$ Jacqueline Kisato $(\mathrm{PhD})^{2} \quad$ Godwin Gbadagba $^{3}$ \\ 1. Department of Vocational Education, St. Francis College of Education P.O. Box 100, Hohoe, Ghana \\ 2. Department of Fashion, Design and Marketing, Kenyatta University, P.O. Box 43844-00100 Nairobi Kenya \\ 3. Department of Vocational Education, Dambai College of Education P.O. Box 84, Dambai, Oti Region
}

\begin{abstract}
The aim of this study was to explore the influence of pedagogical content knowledge competencies of Ghana senior high school textile teachers on the modernisation of indigenous Ghanaian textile industry. A crosssectional survey design was used to collect both qualitative and quantitative data. The study targeted senior high school textile teachers, senior high school textile graduates and heads of visual arts department. The sample size for the study was 243 (225 teachers, 12 textile graduates \& $6 \mathrm{HoDs}$ ). Questionnaire, interview guide and observation were the research instruments employed for data collection. The result of $\mathrm{H}_{01}$ indicated that the pedagogical content knowledge of textile teachers has influence on the skills textile graduates needed to modernise the indigenous textile industry. The findings of the study also signposted that the pedagogical content knowledge of the textile teachers cannot enable the textile students to acquire the requisite skills needed to modernise the indigenous textile industry. The findings of the study indicated most of the Ghana senior high schools lacked textile training facilities and resources needed to modernise the indigenous textile industry. The study recommended that ministry of education should periodically sponsor textile teachers to have industrial attachments in both local and international renowned textile industries to learn modern content knowledge of textile manufacturing. There should also be periodic capacity building workshops on vocational skills pedagogical knowledge to enable the textile teachers effectively transmit the content knowledge to their students effectively.
\end{abstract}

Keywords: Content knowledge, pedagogical knowledge, pedagogical content knowledge.

DOI: $10.7176 / \mathrm{ADS} / 78-01$

Publication date: November 30th 2019

\subsection{Background to the study}

The scope of Ghana senior high school textiles training is designed to offer the learners the opportunity to gain enough creative skills and ability in textiles to practise vocation at the end the school. The Ghana senior high school textile programme is also designed to help students contribute to the growth of science and technology, modernise indigenous textile industry, the economy, social well-being and our culture identity (Curriculum Research and Development Division, 2010). To realise the rationales of Ghana senior high school textile training, textile teachers' pedagogical content knowledge competencies must be conformed with modern technological mode of textile production in terms of processes, quantity, quality, use of modern equipment or machines, and packaging.

According to Ismail and Rasul (2017), pedagogical content knowledge competencies of teachers are the driving force behind graduates' performance in relation to the growth of industries. Pedagogical content knowledge of teachers comprises capability in conveying the theoretical approach, personal understanding and adaptive reasoning of the subject matter (Kathirveloo, Puteh, \& Matematik, 2014). Pedagogical content knowledge is a blend of subject matter, students' knowledge and a diversity of how subject matter is conveyed to students in and outside the classroom (Yusof \& Zakaria, 2010).

According to Enqvist (2015), pedagogical content knowledge of a teachers means blending of subject matter and instructional approaches into an understanding of how certain themes, problems, or issues are organised, represented, and modified to the varied interests and abilities of learners, and presented for instruction. Kultsum (2017) states that pedagogical content knowledge is the amalgamation between content knowledge and pedagogical knowledge of the teachers in delivering a subject matter in accordance to the ability and interest of learners. Pedagogical content knowledge is the technique of describing and articulating a topic methodically that makes it comprehensible for learners (Kumari, 2015).

Lankford (2010) opines that Pedagogical content knowledge is the knowledge teachers possess which permits them to impart subject matter effectively within a discipline as opposed to the knowledge of the discipline itself. 


\subsection{Statement of the problem}

The Ghana senior high school textile training curriculum is designed to aid the students to develop creative skills and ability in textiles that can lead to the modernise of the indigenous textile industry due to the keen competition of the textile industry internationally has over the years which led to the defeat and nearly collapse of indigenous Ghanaian textile industry. The textile programme at the senior high level is also designed to contribute to the evolution of science and technology, to create more jobs and eradicate poverty (Curriculum Research and Development Division, 2010).

However, there have been numerous criticisms over the years that the pedagogical content knowledge of textile teachers are responsible for senior high school textile graduates inability to require skills needed to modernise the indigenous textile industry. Whereas there have been several strong criticisms of the pedagogical content knowledge of textile teachers, scarce studies exist to support these criticisms. This study intended to find out if the pedagogical content knowledge of Ghana senior high school textile teachers is responsible for textile graduates inability to acquire current skills to bring innovations and modernisation to the indigenous Ghanaian textile industry.

\subsection{Research objectives}

i. To establish the influence of pedagogical content knowledge of Ghana senior high school textile teachers on skills graduates needed to modernise the indigenous textile industry.

ii. To discuss the challenges confronting Ghana senior high school textile training.

\subsection{Null hypothesis}

To obtain the results for objective one, the following null hypothesis was formulated and tested:

$\mathrm{H}_{\mathrm{O} 1}$ : The pedagogical content knowledge of textile teachers has no influence on the skills textile graduates needed to modernise the indigenous textile industry.

\subsection{Research design}

Cross-sectional survey design was used in this study to collect both qualitative and quantitative data from respondents. The cross-sectional design was employed because it enables the researchers to obtain a representative sample by taking a cross-section of the population and all the measurements for a sample participant are gained at a single point in time (Sedgwick, 2014). According to Hemed (2015), cross-sectional survey can enable a researcher to determine the number of people affected by a problem and whether the rate of the incident differs across groups or population characteristics.

\subsection{Target population}

According to Asiamah, Mensah and Oteng-Abayie (2017), a target population is defined as a group of people about which some data is required to be discovered. Target population is a whole set of subjects that have particular common features well-defined by the sampling criteria established by the researcher. This study targeted 346 senior high school textile teachers, 6 visual arts department HoDs and 12 textile graduates who are owners/managers of indigenous textile industry in the three regions namely Volta, Ashanti and Northern regions. Table 1 indicates the breakdown of the groups in the target population.

Table 1: Target Population

\begin{tabular}{lc}
\hline Group & Population \\
\hline Senior High School Textile Teachers & 346 \\
Senior High Textile Graduate & 12 \\
HoDs & 6 \\
\hline Total & $\mathbf{3 6 4}$ \\
\hline
\end{tabular}

\subsection{Sampling techniques}

This study employed purposive sampling, simple random sampling, and snowball to get relevant information needed for study. The purposive sampling was used to select only senior high schools offering the textile programme and heads of Visual Arts department in the target population. According to Etikan, Musa, and Alkassim (2016), purposive sampling comprises recognition and selection of participants or groups of participants that are expert and up-to-date with a phenomenon of interest.

Simple random sampling was used to randomly select the senior high school textile teachers because the researcher could not accumulate data from all 346 senior high school textile teachers in the three regions targeted. Simple random sampling is a technique of sampling in which each individual in a target population has an equal probability of inclusion in sample (Taherdoost, 2016).

Snowball sampling technique was employed to trace 12 senior high school graduates working in the indigenous textile industry in Volta, Ashanti and Northern regions of Ghana to provide relevant information for 
this study. This sampling was employed because getting information about the location of the textile graduates was difficult for the researcher. Snowball sampling is a technique of collecting data to access specific groups of people when the target population cannot be found in a particular place (Limboro, 2012; Naderifar, Goli \& Ghaljaei, 2017). In this sampling technique, the researcher asks each subject to give him or her access to his colleagues from the same population (Elfil \& Negida, 2017).

\subsection{Sample size}

Sampling was carried out in this study because the target population was a very scattered population and so it was impossible to collect data from all the 346 textile teachers in the target population. A sample is a collection of individuals from a population one is interested to study (Malone \& Coyne, 2016). Hill (2012) states that with the population of 30 to 500 , the use of about $10 \%$ size of the population is recommended. Bosibori (2012) indicates that for little populations, a sample size of about $20 \%$ of the inhabitants is an excellent representation whilst for huge populations a sample size of $10 \%$ representative is adequate.

The researcher therefore, sampled $50 \%$ of the textile teachers' population out of 346 to obtain 173. However, the researcher hypothesised that some teachers may not return their questionnaires and so the sample size for the teachers was 30\% upward adjusted to cater for non-compliance (McConnell \& Vera-Hernandez, 2015). The teachers sample size for the study was 225. Table 2 below indicates the breakdown of the total sample size.

Table 2: Sampling Grid of Participants for the Study

\begin{tabular}{lrr}
\hline Participants & Population & Sampled \\
\hline SHS Textile Teachers & 346 & 225 \\
SHS Textile Graduates & 12 & 12 \\
HODs & 6 & 6 \\
\hline Total & $\mathbf{3 6 4}$ & $\mathbf{2 4 3}$ \\
\hline
\end{tabular}

\subsection{Instrumentation}

This study employed 3 data collection instruments namely; questionnaire, interview guide and observation. The questionnaire was used to collect data from the Ghana senior high school textile teachers about their pedagogical content knowledge. The interview guide was used to amass data from the senior high school textile graduates working in the indigenous textile industry about the pedagogical content knowledge of the textile teachers and the challenges they encountered in studying textile during their training at the senior high schools. The observation was used to study the training facilities and resources the researcher visited for data collection. According to Anum (2017), research instruments are the instruments or tools that aid a researcher to collect his or her data and they include questionnaire, interview guide, and observation.

\subsection{Data analysis}

The data collected were analysed quantitatively and qualitatively to address the objectives. Statistical Package for Social Sciences (SPSS) was employed to analyse the quantitative data gathered from close-ended questionnaires. Inferential statistic was used in the data analysis. Pearson point-biserial correlation was used to test the two null hypotheses formulated at $p<0.05$ alpha level of significance. The open-ended questionnaires and interview conducted were transformed to create records. The transformation of raw data was done by hand under the various themes.

\subsection{Findings and discussions \\ 1.11.1 Findings}

$\mathrm{H}_{\mathrm{O} 1}$ : The pedagogical content knowledge of textile teachers has no influence on the skills textile graduates needed to modernise the indigenous textile industry.

To obtain the results of $\mathrm{Ho}_{1}$ which is in line with objective 1, point-biserial correlation coefficient was used because this statistical tool enables researchers to test the relationship between independent variables and dependent variables in a research.

Table 3: Point-biserial correlation between pedagogical content knowledge of textile teachers and the skills textile graduates needed to modernise the indigenous textile industry.

\begin{tabular}{|c|c|c|}
\hline Variable & $\begin{array}{r}\text { Point-Biserial } \\
\text { Correlation }(r)\end{array}$ & $\begin{array}{l}\text { Sig. (2- } \\
\text { tailed) }\end{array}$ \\
\hline $\begin{array}{l}\mathrm{H}_{\mathrm{O} 1} \text { : The pedagogical content knowledge of textile teachers has no influence } \\
\text { on the skills textile graduates needed to modernise the indigenous textile } \\
\text { industry. }\end{array}$ & $.808 * *$ & .001 \\
\hline
\end{tabular}

From table 3 are the results obtained by tests conducted using Pearson's Point-biserial correlation analysis. 
The findings indicated the correlation coefficients and the significance of the relationship between the independent and dependent variables. The results showed that there is a positive correlation between the pedagogical content knowledge of textile teachers and the skills textile graduates needed to modernise the indigenous textile industry $(\mathrm{r}=.808, \mathrm{n}=206, \mathrm{p}=.01)$. The results further show that the correlation is strong and significant even at 0.01 significance level.

The null hypothesis HO1 that stated the pedagogical content knowledge of textile teachers has no influence on the skills textile graduates needed to modernise the indigenous textile industry is therefore, rejected and the conclusion is that there is a strong constructive correlation between the pedagogical content knowledge of textile teachers and the skills textile graduates needed to modernise the indigenous textile industry. A positive correlation means that as one variable increases, the other variable also increases while a negative correlation indicates that as one variable increases, the other decreases. In this regard, a positive correlation coefficient $(r=$ 0.808) recorded means the more competent the textile teachers are in pedagogical content knowledge, the more textile students would acquire skills needed to modernised the indigenous textile industry.

Objective 2: To discuss the challenges confronting Ghana senior high school textile training. Table 4: Textile teachers' response on SHS challenges of textile training in Ghana

\begin{tabular}{|c|c|c|c|c|}
\hline & Statement & Agreed & None & Disagreed \\
\hline 1. & $\begin{array}{l}\text { My school has a well equipped ICT lab for extile CAD/ CAM } \\
\text { training needed to modernise the indigenous textile industry. }\end{array}$ & $70(42.9 \%)$ & - & $136(57.1 \%)$ \\
\hline 2. & My school authorities supply materials for practicals. & $55(26.7 \%)$ & - & $151(73.3 \%)$ \\
\hline 3. & $\begin{array}{l}\text { My school has enough textile tools and equipment used in } \\
\text { indigenous industry }\end{array}$ & $94(45.7 \%)$ & - & $112(54.3 \%)$ \\
\hline 4. & There are enough published textile textbooks in the system. & $76(36.8 \%)$ & - & $130(63.2 \%)$ \\
\hline 5 . & $\begin{array}{l}\text { My school has a permanent and well equipped textile studio for } \\
\text { practical works. }\end{array}$ & $53(25.7 \%)$ & - & $153(74.3 \%)$ \\
\hline 6. & $\begin{array}{l}\text { The time and number of periods allotted to textile programme is } \\
\text { sufficient for practical works. }\end{array}$ & $42(20.4 \%)$ & - & $164(79.6 \%)$ \\
\hline 7. & $\begin{array}{l}\text { I attend organised workshop and industrial attachment } \\
\text { periodically to update my skills. }\end{array}$ & $91(44.2 \%)$ & & $115(55.8 \%)$ \\
\hline
\end{tabular}

The results in table 4 showed that majority of the teachers $(\mathrm{N}=136,57.1 \%)$ said their schools were not having a well-equipped ICT lab for textile CAD/CAM training needed to modernise the indigenous textile industry whilst $(\mathrm{N}=70,42.9 \%)$ said they have a well-resourced ICT lab for CAD/CAM training. Majority of the textile teachers $(\mathrm{N}=151,73.3 \%)$ felt that school authorities never supply textile learning materials for effective practical works while fewer number $(\mathrm{N}=55,26.7 \%)$ stated authorities supply materials. Majority of textile teachers $(\mathrm{N}=112,54.3 \%)$ also indicated that their schools do not have enough textile tools and equipment use in indigenous industry while ( $\mathrm{N}=94,45.7 \%)$ said they have enough textile tools and equipment.

With regard to availability of enough published textile textbooks in the system, higher number of teachers $(\mathrm{N}=130,63.2 \%)$ disagreed to the statement while $(\mathrm{N}=76,36.8 \%)$ agreed with the statement. It was also revealed that majority of the textile teachers $(\mathrm{N}=153,74.3 \%)$ said their schools have no permanent and well equipped textile studio for practical works while $(\mathrm{N}=53,25.7 \%)$ said they have permanent and well equipped studio for practical works. A larger number of textile teachers $(\mathrm{N}=164,79.6 \%)$ felt that the time and number of periods allotted to textile programme is not sufficient for practical works but $(\mathrm{N}=42,20.4 \%)$ affirmed to the statement. Most teachers $(\mathrm{N}=115,55.8 \%)$ opined that workshops and industrial attachments were not organised for them periodically to update their skills while $(\mathrm{N}=91,44.2 \%)$ said they attended organised workshops and industrial attachment periodically. The results in table 4 indicated that teachers had high negative response to all the statements with mean scores ranging from 3.0. This clearly showed that apart from the pedagogical content knowledge of textile teacher, training facilities and resources are also another major challenges confronting the skills textile graduates needed to modernise the indigenous Ghanaian textile industry.

\subsection{Discussion}

Objective 1: To establish the influence of pedagogical content knowledge of Ghana senior high school textile teachers on skills graduates needed to modernise the indigenous textile industry.

The modernisation of any industry are enriched by developing the knowledge and skills of its labour-force through an effective training receive in the classroom. Both the quantitative and qualitative data obtained from 
the textile teachers, graduates and heads of visual arts department indicated that the pedagogical content knowledge of the textile teachers cannot enable the textile students to acquire the requisite skills needed to modernise the indigenous textile industry. It was discovered that most of the textile teachers who attended polytechnic (now technical universities) have adequate practical skills to help bring some modernisation to the indigenous textile industry but lack pedagogical knowledge to deliver the content knowledge effectively since most them study no pedagogy related courses during their polytechnic education. It was also found out that majority of those teachers who went to traditional university have the pedagogical knowledge but lack sufficient practical skills to teach and so they teach more theory that practical skills needed to modernise the indigenous textile industry. As a result, textile graduates were not effectively equipped with practical skills to modernise the indigenous textile industry. The present finding concur to Audu (2014) who published that graduates from skill training institutions lack skills needed to transform indigenous industries because the pedagogical content knowledge of teachers in technical and vocational training institutions have not succeeded in imparting constructively on practical skills achievement of the graduates. The finding is also in support of Idris \& Rajuddin, (2012) who opine that industrial employers have constantly express their worry about the quality of the current technical and vocational graduates not having appropriate skills required for employment in the industries.

This finding also is in agreement with Netherland Organization for International Cooperation in Higher Education (2010) that explains that there are numerous challenges confronting graduates of skill training institutions in terms of practical skills acquisition in many developing countries since the skills they acquired from school are not relevance to the needs of industries. This finding is also in agreement with Ideh (2013) who stated that most of the technical and vocational graduates are considered to be ill- equipped and declared unemployable due to the quality of training received in the classroom.

Objective 2: To discuss the challenges confronting Ghana senior high school textile training.

The qualitative data obtained from open-ended questionnaire and interview guide indicated that Ghana senior high school textile training has a lot of challenges. The first challenge was that most of the senior high schools lack permanent textile lab or studios for effective practical activities. There were also lack of ICT lab or wellequipped ICT lab for students to be trained in CAD/CAM that can help them bring modernisation to the indigenous textile industry.

Again, it was discovered that most senior high schools lack textile tools/equipment and materials for effective delivering of the textile curriculum. As a result, students were forced to purchase their own training resources which at the end put a lot of financial burdens on the few students that can afford the purchase of the tools and materials. Students that cannot afford textile training tools and materials stayed idle or in some cases not allowed to attend practical lessons hence the inability of most of the textile graduates to acquire skills that can modernise the indigenous textile industry.

Another challenge was that the time allotted to the textile practical lessons is not sufficient to achieve the objectives of the practical lesson. As a result, few textile teachers who have adequate pedagogical content knowledge resort to use lecture and discussion methods of teaching for practical topics so as to cover the textile syllabus on time.

The study further revealed that textile teachers do not attend workshops and industrial attachments periodical to update their skills. Most of these teachers had completed their training over ten years ago and so lack modern skills students required to bring innovations to the indigenous textile industry. Another most important challenge facing the textile training institutions is lack of current published textbooks to equip students with current knowledge and skills needed at the indigenous textile industry. The findings in this study agrees with Netherland Organization for International Cooperation in Higher Education (NICHE, 2010) which came out with a paper that there are several challenges facing graduates from technical and vocational institutions in most developing countries in terms of practical skills acquisition due to lack of training tools/equipment, poor resource materials and also training acquired are theoretical instead of practical.

NICHE (2010), continues that inadequate training tools/equipment, facilities and training materials lead to learners' congestion during practical lessons, with greater number of the learners only observing the demonstration instead of hands-on practice. The present finding is also in agreement with Munishi (2016) who postulates that insufficient provision of teaching and learning capitals in skill training institutions is yet another obstruction affecting job skills acquisition of technical and vocational education graduates. Again, the present findings are in support of Anindo (2016) who states that transmitting skills to students requires tools, equipment, well-equipped studio and effective utilisation of these facilities hence the absence of all these in most technical and vocational institutions would badly affect the quality and relevance of the skills acquired by the graduates.

\subsection{Conclusion}

The study made the following important conclusions based on the above findings:

i. the pedagogical content knowledge of the Ghana senior high school textile teachers had a significant influence on senior high school graduates participation in the modernisation of the indigenous 
Ghanaian textile industry.

ii. There are many challenges facing Ghana senior high school textile training.

\subsection{Recommendations}

The following recommendations were made based on the results and conclusions of the study:

i. ministry of education should periodically sponsor textile teachers to have industrial attachments in both local and international renowned textile industries to learn modern skills of textile manufacturing.

ii. There should also be periodic capacity building workshops on vocational pedagogical strategies to enable the textile teachers to effectively transmit modern skills to the students.

iii. the policy on visual arts subject combination should be abolished to enable students interested in studying textiles to do so.

\section{REFERENCES}

Anindo, J. (2016). Institutional factors influencing acquisition of employable skills by students in public technical and vocational education and training institutions in Nairobi County, Kenya (Master's thesis). School of Education, University of Nairobi.

Anum, G. (2017). Research instruments for data collection. Department of Fine Art and Media Art Technology, Kwame Nkrumah University of Science and Technology.

Asiamah, N., Mensah, H.K. \& Oteng-Abayie, E.F. (2017). General, target, and accessible population: Demystifying the concepts for effective sampling. The Qualitative Report, 22 (6), 1607-1622.

Audu, R. (2014). Assessment of the teaching methods that influence the acquisition of practical skills. Asian Social Science, (21), 35-41.

Bosibori, O.E. (2012). Role of product range, network associations and marketing strategies in business performance of textile handicraft traders in Nairobi, Kenya ( $\mathrm{PhD}$ thesis). School of Applied Human Sciences, Kenyatta University.

Curriculum Research and Development Division, (2010). Teaching syllabus for textile (SHS1-3). Accra, Ghana: Ministry of Education.

Elfil, M.\& Negida, A. (2017). Sampling methods in clinical research: An educational review. Shahid Beheshti, University of Medical Sciences.

Enqvist, J. (2015). Pedagogical content knowledge. Vocational Education Unit, University of Applied Sciences, HAMK.

Etikan, I., Musa, S.A. and Alkassim, R.S. (2016). Comparison of convenience sampling and purposive sampling. American Journal of Theoretical and Applied Statistics, 5 (1), 1-4.

Hemed, M. (2015). Cross-sectional studies. Tanzania: GFMER.

Hill, R. (2012). What sample size is "enough" in internet survey research? Interpersonal computing and technology. An Electronic Journal for the 21st Century, 6 (3-4), 1-10.

Ideh, V. (2013). Students' perception of strategies for improving delivery of industrial work experience in Delta State University, Abraka. Nigeria. Vocational Association Journal, 18 (2), 237- 242.

Idris, A. \& Rajuddin, M.R. (2012). The Influence of teaching approaches among technical and vocational education teachers towards acquisition of technical skills in Kano State-Nigeria. Journal of Education and Practice, 3(16), 160-165.

Ismail, K \& Rasul, M.M. (2017). Malaysian teachers' competency in technical vocational education and training: A review. London: Taylor \& Francis Group.

Kathirveloo, P. Puteh,M \& Matematik, F.S. (2014). Effective teaching: Pedagogical content knowledge. Proceeding of International Joint Seminar Garut, Garut, Indonesia. 21 September 2014.

Kultsum, U. (2017). The concept of pedagogical content knowledge (PCK): Recognising the English teachers' competences in Indonesia. Advances in Social Science, Education and Humanities Research, 134, $55-59$.

Kumari, K. (2015). Impact of pedagogical content knowledge of teachers on pedagogical transitional problems of undergraduate students. Dayalbagh Educational Institute, Deemed University.

Lankford, D. (2010). Examining the pedagogical content knowledge and practice of experienced secondary biology teachers for teaching diffusion and osmosis. The Faculty of the Graduate School, University of Missouri.

Limboro, C.M. (2012). Skills training in engineering courses in institutes of technology and the labour market requirements in Kenya (Ph.D thesis). School of Education, Kenyatta University.

Malone, H.E. \& Coyne, L. (2016). Fundamentals of estimating sample size. Retrieved from https://www.researchgate.net/publication/303312866.

McConnell, B. \& Vera-Hernandez, M. (2015).Going beyond simple sample size calculation: A Practioner's guide. Institute for Fiscal Studies Working Paper W15/17.

Munishi, E.J. (2016). Factors contributing to lack of employable skills among technical and vocational education 
(TVET) graduates in Tanzania. Business Education Journal, 1 (2), 1-19.

Naderifar, M., Goli H. \& Ghaljaei, F. (2017). Snowball sampling: A purposeful method of sampling in qualitative research. Strides in Development of Medical Education 14 (3) 1-6.

Netherland Organization for International Cooperation in Higher Education (2010). Strategy of Technical Vocational Education and Training. Amsterdam: NOICHE.

Sedgwick, P. (2014). Cross sectional studies: Advantages and disadvantages. Centre for Medical and Healthcare Education, St George's, University of London.

Taherdoost, H. (2016). Sampling methods in research methodology: How to choose a sampling technique for research. Berlin, Germany: ResearchGate.

Yusof, Y.M. \& Zakaria, E. (2010). Investigating secondary mathematics teachers' pedagogical content knowledge: A Case Study. Journal of Education and Sociology, 32-39. 